Review Article

\title{
Policy delivery for low carbon energy infrastructure in the UK, april 5th 2013: Conference overview
}

\author{
Raphael J. Heffron ${ }^{\mathrm{a}, \mathrm{b}, *}$, Angus Johnston $^{\mathrm{c}}$, Darren McCauley ${ }^{\mathrm{d}}$, Kirsten Jenkins ${ }^{\mathrm{d}}$ \\ ${ }^{a}$ University of Stirling, UK \\ ${ }^{\mathrm{b}}$ Electricity Policy Research Group, University of Cambridge, UK \\ ${ }^{\mathrm{c}}$ Faculty of Law, University of Oxford, UK \\ ${ }^{\mathrm{d}}$ Department of Geography and Sustainable Development, University of St. Andrews, UK
}

\section{A R T I C L E I N F O}

\section{Article history:}

Received 23 May 2013

Accepted 24 May 2013

Available online 21 June 2013

Keywords:

Energy infrastructure

Policy delivery

Low-carbon

\begin{abstract}
A B S T R A C T
The ambition of this conference was to deliver a first examination of how policy is delivered in the context of low-carbon energy infrastructure in the UK. The UK has been developing policy in this area since 2002 (Heffron, 2013). Finally, as the decade passed, in November 2012 an Energy Bill was put before the UK Parliament. One of the chief purposes of this Energy Bill is to establish the right environment for new electricity generation infrastructure in the low-carbon sector. There is significant debate on how this will be achieved and, indeed, whether this piece of legislation will actually deliver this outcome. This conference aimed to examine the dynamics of policy delivery. Throughout the day, there was entertaining discussion as a variety of conference presenters provided interesting contributions on how to deliver such policy goals. In total, there were twelve speakers throughout the day representing the UK (University of Oxford, Pinsent Masons Law Firm, University of Stirling, University of Dundee and University of Aberdeen), and also those who provided lessons from abroad from the University of Copenhagen, Central European University, Milieu Ltd., Pillsbury Law Firm (Washington DC, US) and the Conservation Law Foundation (MA, US).
\end{abstract}

(c) 2013 Elsevier Ltd. All rights reserved.

\section{Contents}

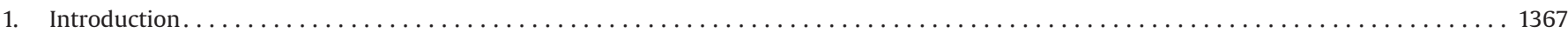

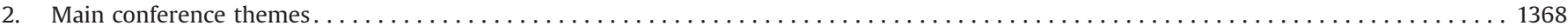

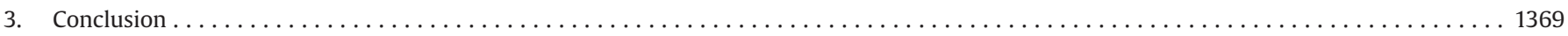

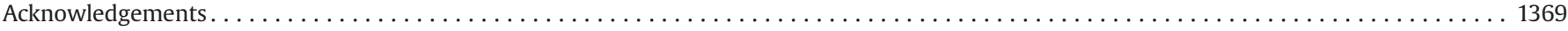

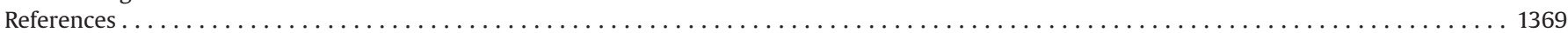

\section{Introduction}

The ambition of this conference was to deliver a first examination of how policy is delivered in the context of low-carbon energy infrastructure in the UK. The UK has been developing policy in this area since 2002 (Heffron, 2013). Finally, as the decade passed, in November 2012 an Energy Bill was put before the UK Parliament. One of the chief purposes of this Energy Bill is to establish the right environment for new electricity generation infrastructure in the low-carbon sector.

There is significant debate on how this will be achieved and, indeed, whether this piece of legislation will actually deliver this

\footnotetext{
* Corresponding author at: University of Stirling, UK. Tel.:+ 44 (0) 1786467591.

E-mail addresses: raphael.heffron@stir.ac.uk, raphael.heffron@gmail.com (R.J. Heffron).
}

outcome. This conference aimed to examine the dynamics of policy delivery. Throughout the day, there was entertaining discussion as a variety of conference presenters provided interesting contributions on how to deliver such policy goals.

In total, there were twelve speakers throughout the day representing the UK (University of Oxford, Pinsent Masons Law Firm, University of Stirling, University of Dundee and University of Aberdeen), and also those who provided lessons from abroad from the University of Copenhagen, Central European University, Milieu Ltd., Pillsbury Law Firm (Washington DC, US) and the Conservation Law Foundation (MA, US). ${ }^{1}$

\footnotetext{
${ }^{1}$ The conference was held on April 5th 2013 at the University of Stirling, UK. For more information please see the conference website: http://www.stir.ac.uk/ cehp/newsandevents/previous-events/policy-delivery/. The speakers were as follows: Anite Rønne, Professor in Energy Law, University of Copenhagen; Helen G.
} 


\section{Main conference themes}

The main focus of the day was on new low-carbon electricity generation infrastructure and-as David Robson, Helen Cook, and Malcolm Keay stated-there is a need to view installation of such infrastructure within the evolving context of local, regional, national and international systems. An example of this was Jennifer McGuinn's presentation on the EU's TEN-E regulations.

(1) Policy delivery

The essence of the conference was on policy delivery for new low-carbon electricity generation infrastructure. This is an area that the government is currently trying to finalise and secure agreement upon in the current Energy Bill that is before Parliament in the UK. In terms of policy delivery, there were a number of topics that repeatedly arose throughout the day.

(i) The level at which policy is developed, delivered and "enforced", and indeed influenced:

a. the level can operate as a constraint or delay but also as an opportunity;

b. for example, the US shale gas surplus may in the future lead to exports.

(ii) Time-frames involved:

a. policy delivery and formulation are a process, and their timeframe needs to be considered alongside that for actual deployment and operationalisation;

b. the assets created typically have a very long life-span;

c. policy should offer predictability, yet must also be flexible in making provision for transition (for example, to the lowcarbon aims);

d. an example of the latter was stated by Shanna Cleveland, who explored the emergence of shale gas and decline of oil and coal in New England in the US.

(iii) Predictability and certainty

a. political clarity and commitment is essential to ensure development of certain technologies and projects;

b. equally, it is important to secure effective system organisationfor example, such as the value chain of a particular industry;

c. and it is vital to send appropriate investment signals.

(iv) Uncertainty and unfamiliarity:

a. there are new challenges in planning a low-carbon future, and these are typically ones where there is a limited experience upon which to draw;

b. there is a need to move into an experimental "learning by doing" approach in some cases of policy process;

c. dynamics and fluctuations in global markets, and the geopolitical dimension have to be considered. (footnote continued)

Cook, Senior Associate, Nuclear Energy, Pillsbury Winthrop Shaw Pittman LLP, Washington DC, USA; Angus Johnston, CUF Lecturer, Faculty of Law, University of Oxford, UK; Jennifer McGuinn, Milieu Ltd., Law and Policy Consulting, Brussels, Belgium; Michael LaBelle, Professor in Environmental Sciences and Policy, Central European University, Budapest, Hungary; Malcolm Keay, Senior Research Fellow, Oxford Energy Institute, University of Oxford, UK; Christopher White, Partner, Pinsent Masons LLP, London, UK; Shanna Cleveland, Attorney-at-Law, Conservation Law Foundation, Boston, MA, USA; Olivia Woolley, Lecturer in Law, University of Aberdeen, UK; David W Robson, Head of Energy and Environmental Foresight, Scottish Government, UK; Geoffrey Wood, Centre for Energy, Petroleum, and Mineral Law and Policy (CEPMLP), University of Dundee, UK; and Raphael J Heffron, Lecturer in Law, University of Stirling, UK.

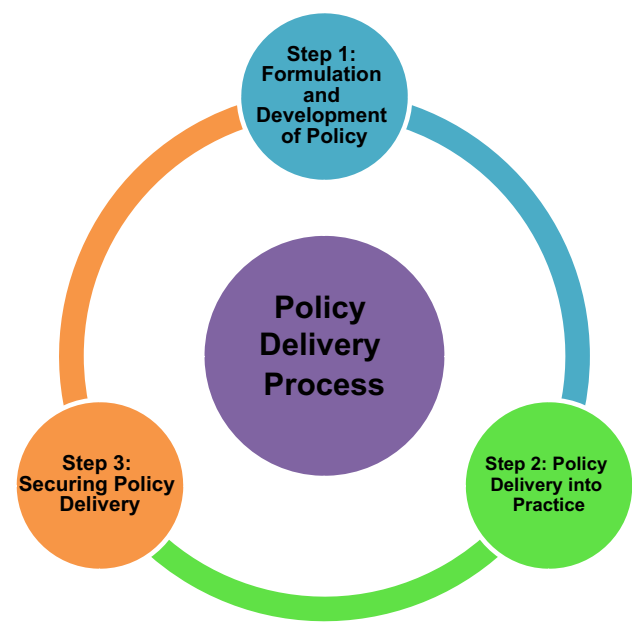

Fig. 1. The three steps of achieving policy delivery.

(2) A policy triangle for achieving policy delivery

An interpretation of the mechanisms and process for policy delivery was evident from the proceedings of the day. A triangle as demonstrated in Fig. 1 identifies three fundamental steps in achieving policy delivery.

Step 1: formulation and development of policy

- From the outset, there is a requirement to obtain and analyse information.

- Participation and representation are crucial: for example, in Denmark (Anite Rønne), there is extensive experience of public information provision concerning wind farm development.

- Institutional involvement is a key element: i.e. an institution should co-ordinate (securing a systematic approach-G. Wood) its activities at local, regional, national and international level.

- The aim(s) of policy should be clear:

$\circ$ the definition and scope of policy need to be outlined at the outset-political and legal implications and effectiveness need to be considered (Raphael Heffron);

$\circ$ if there are multiple goals, one must consider interactions and incompatibilities (Raphael Heffron);

- priorities at different levels (e.g. EU and its various Member States) may differ regarding different goals and aspects (supply security, environmental sustainability, competition and liberalisation, etc.);

- one should try to avoid or at least ameliorate perverse consequences when policies (which are individually laudable) interact in undesirable ways: e.g. puruisng responses and fine tuning in other areas to resolve problems, rather than watering down energy law and policy (e.g. social policy to address energy poverty).

- as Malcolm Keay advocated, the UK needs a more integrated approach in aiming for the multiple goals of its policy; and the question arises (Angus Johnston) are too many Cinderellas going to the Ball where there are too many different dances overlapping on the same floor?

Step 2: policy delivery: putting it into practice

- At which level?

- Private or public; State or EU level.

- In which ways?

- legislation drafted in a detailed and prescriptive manner, or delaying, power-conferring and proactive. 
- Reliability and consistency in policy

$\circ$ an excellent example of this was Anite Rønne's presentation on wind energy development in Denmark, where political consensus and the role of the local community in participation and ownership contribute to the stability of long-term plans and planning more generally.

- Constraints on practical implantation

- supra-national and international law, treaties, obligations, diplomacy and politics can all act as constraints. As Chris White suggested, EU State Aid rules are one such constraint being considered at the moment regarding UK plans under the Energy Bill.

Step 3: securing policy delivery

- Monitoring of performance and compliance: reporting, regulation and verification.

- Information provision and explanation: in essence, aiming to achieve accountability which will feed back into future adjustment of law and policy, while also providing information to make the public aware of the measures taken, the reasons for such measures, and their implications.

- Incentives and reassurances: subsidies and compensation for loss, etc.

- The "Lawyer's obsession": rights, duties and enforcement (through mechanisms and institutions). This is vitally important as it can feed its way back into the system and discourage investment, research and development activity, and slow planning processes. Equally, reassurances about robust legal protections may also be crucial to encourage investments and activities, in the face of potential policy instability and fluctuation (e.g. the UK courts' rejection of a government attempt retrospectively to reduce certain renewables subsidy levels).

\section{Conclusion}

This conference is the first in series of planned events around the theme of policy delivery on energy policy, which will also address energy justice. There are significant lessons for achieving more effective policy delivery that emanate from this conference, and with the current flux over new energy infrastructure that is ongoing in the UK, this conference and the lessons generated are timely.

What was contained in the presentations throughout the day was the importance of policy that demonstrates the government's commitment, and that it is consistent and stable. This will have a significant effect on the outcome of policy delivery. The conference also highlighted three central steps (as outlined in Fig. 1) that lead to achieving effective policy delivery. Binding targets, contracts with government, and legislation that generates rights and entitlements which are protectable are central to securing policy delivery. Finally, the focus on policy delivery as a research topic is an area that requires more research, and on that is open to different academic disciplines, but in particular insights from law, economics, politics, geography and environmental sciences will prove important in addressing policy questions in an integrated and co-ordinated fashion.

\section{Acknowledgements}

The authors are grateful to the ESRC and the law firm Simpson and Marwick for supporting the conference.

\section{References}

Heffron, R.J., 2013. The application of contrast explanation to energy policy research: UK nuclear energy policy 2002-2012. Energy Policy 55, 602-616. 